\title{
A developmental analysis of communication between mothers and infants with Down's syndrome
}

Gerald Mahoney, PhD

Assistant Professor

Department of Special Education

The University of Michigan

Ann Arbor, Michigan
ATHOUGH RESEARCH indicates that A mothers contribute to the process of language acquisition by reducing the complexity of their language input to a level that is commensurate with their children's language competence and by responding appropriately to selected parameters of their children's speech (Cross, 1977; Furrow, Nelson, \& Benedict, 1979), it has not been definitively established that maternal speech patterns are causally related to children's rate of language development. However, the universality of this phenomenon as well as the apparent didactic value of maternal speech patterns have led to a general consensus that this is one of several critical factors that influence children's acquisition of language (Cross, 1978; Moerk, 1976).

This article is a longitudinal investigation of the quality of the language with which two mothers addressed their Down's syndrome children during the second year of life.

TECSE, 1983, 3(1), 63-76

(C) 1983 Aspen Systems Corporation 


\section{STUDIES OF MATERNAL SPEECH OF MOTHERS OF MENTALLY HANDICAPPED INFANTS}

Maternal speech is hypothesized to be a special problem for mothers of mentally handicapped infants because of the unique factors that complicate the adjustments that they must make to these children (Mahoney \& Seely, 1976). That is, mothers may be distressed or otherwise psychologically distraught over the birth of their child, they may have inappropriate attitudes or expectations regarding their children's development, or they may have difficulty sustaining appropriate interaction because their children are unresponsive or emit ambiguous signals (Mahoney, 1975). It is unlikely however, that all mothers are inappropriate in the manner in which they speak to their children, since many are able to deal with these problems adequately soon after the birth of their children. Although early intervention programs typically include parent education components, many parents are already extraordinarily sensitive and competent in their interaction with their children and are thus not in need of assistance in this area.

In spite of the range of individual differences in the ability of mothers to interact with their mentally handicapped children, investigations of the quality of their maternal speech have assumed that these mothers constitute a homogeneous group (Buckhalt, Rutherford, \& Goldberg, 1978; Petersen \& Sherrod, 1982; Rondal, 1978). That is, the prevailing research strategy has been to compare the quality of language of a group of mothers of mentally handicapped children with a matched group of mothers of nonhandicapped children. Similarities and differences in various speech parameters have been assumed to constitute a general characteristic of each of the populations.

It has also been assumed that the standard for judging whether parents of mentally hand- icapped children are effective in interacting with their children is the manner in which parents interact with normal children (Buium, Rynders, \& Turnure, 1975; Rondal, 1978). This is an extraordinary assumption, however, since parents of normal children vary considerably in their ability to interact with their children (Nelson, 1973) and since it is quite possible that handicapped children have language learning needs that require special stimulation.

Most investigations of maternal language used to address mentally handicapped children have restricted language assessments to only one observation (see Mahoney \& Seely, 1976). This reflects a belief that the critical issue is the nature of the match between maternal language and child language. However, it is possible that the relationship between the language of mothers and that of their children at one point in time is relatively unimportant, and that the manner in which mothers change the complexity of their language during the course of the children's development is the crucial factor. Thus although a mother of a developmentally delayed child may adequately modify her language to accommodate her child's language competence, the mother may still be deficient insofar as she fails to change her language style developmentally and thus creates a language environment that is not conducive to language change. The failure to assess maternal language developmentally also ignores the possibility that as parents begin to cope more adequately with the problems of adjusting to a mentally handicapped child, their effectiveness at interacting with the child may also improve.

\section{THE PRESENT STUDY}

This article describes the author's study of the characteristics of the language of two mothers of Down's syndrome children during 
the second year of life. The study was designed primarily to address two questions: Is the assumption that parents of developmentally delayed children are homogeneous in the manner in which they speak to their children warranted? (2) Are there developmental changes in the communication between mothers and their children during the second year of life?

It should be noted that even though the study included only two mother-child dyads, the extremely large number of utterances observed for each of the mothers allowed the author to make statistical comparisons to answer each of the two questions. Although the issue of homogeneity might be addressed more effectively with a larger sample, the children in this study were matched on several variables that are thought to influence children's language environments (Nelson, 1973), thus theoretically mitigating the likelihood that the linguistic environment would differ.

Statistical evidence argues against the assumption that mothers of mentally retarded children are homogeneous in their style of speaking to their children.

Statistical evidence that the language environments of these children differ, therefore, argues against the assumption that mothers of mentally retarded children are homogeneous in their style of speaking to their children.

\section{Method}

\section{Subjects}

The subjects for this study were two Caucasian mothers and their Down's syndrome infants, who were both 12 months old at the beginning of the study. Child A, a girl, and Child B, a boy, were matched on several variables that are thought to influence the rate of language development. These variables included age, medical etiology (Trisomy 21), Bayley Mental Development Index (A, 56; B, 51 ), birth order (fourth), number of siblings (3), approximate ages of mothers (A, 34; B, 32), and social class of the families (middle class). Neither of the children had any serious medical or orthopedic problems that might have interfered with his or her level of developmental functioning. The parents of Child A each had 16 years of education; the parents of Child B each had 12 years of education. Both of the children were raised at home by their mothers, and neither of them participated in any type of infant stimulation program during the study.

\section{Procedures}

\section{Observation}

Both parents were contacted when the children were approximately 12 months old. At the initial meeting the children were administered the Bayley Mental Development Scale in their own homes. Following this, each mother-child dyad was observed in free-play interaction at 2-month intervals from the time the children were 14 months old until they were 24 months old, for a total of six observations. Free-play sessions occurred in the living rooms of the subjects' homes and lasted 20 minutes. The rooms were unaltered except that objects and obstacles that could have interfered with the free-play task were removed from the rooms. The subjects were given the same toys to play with at each session. The toys were selected because of their general interest to children between 1 and 2 years of age, and their use required minimal locomotion by the mother and child (e.g., xylophone, toy bus, nesting blocks, books, and stacking rings). Each mother was instructed to play with her child using the toys in any manner she wished.

The language interaction between the mother and child was recorded on one channel of a two-channel stereo cassette tape recorder. 
A high-powered omni microphone located approximately 10 feet from the mother and the child was capable of detecting any vocalization within the room. The second channel was used to record a narrative description of the social interaction and nonvocal communication by an observer who was situated in an unobtrusive area of the room.

\section{Data coding}

Both the vocal interaction and the narration were transcribed by the author. Transcriptions were double-checked by an assistant to ascertain their accuracy. The transcript of the vocal interaction was then coded by two observers who had been trained to achieve at least $85 \%$ interrater reliability on each of the measures. The narration was not coded directly but was used to provide a context for the vocal interaction and to identify nonverbal, communicative signals, such as smiling and gesturing.

Utterances were defined as any verbal or nonverbal attempt to communicate. The boundaries of vocal utterances were marked by pauses, such as those judged to mark the end of sentences or changes in conversational topic. The boundaries of nonverbal utterances were marked by the initiation and termination of behavior. For example, a mother would have to terminate a pointing gesture and initiate a new pointing gesture for two pointing gestures to have occurred. Duration of behavior was not a criterion in determining the number of nonverbal utterances.

Each maternal utterance was coded according to four categories, which are described in Table 1. Two of the categories, mean length of utterance (MLU) and syntactic integrity, were designed to assess maternal syntax. MLU is a measure of syntactic complexity, whereas syntactic integrity gives an index of the percentage of maternal utterances that are grammatically correct.

Functional content is an evaluation of the pragmatic component of maternal speech. Functional content is based on the Maternal Language Classification Scale (Mahoney \& Petersen, 1980) and classifies maternal speech

Table 1. Classification scheme for maternal language

\begin{tabular}{|c|c|c|c|}
\hline $\begin{array}{l}\text { Mean length of } \\
\text { utterance } \\
\text { (MLU) }\end{array}$ & Syntactic integrity & Functional content & Topic \\
\hline $\begin{array}{l}\text { Average number of mor- } \\
\text { phemes in each utter- } \\
\text { ance according to Brown } \\
\text { (1973) }\end{array}$ & $\begin{array}{l}\text { A) One-word utterance } \\
\text { B) More than one-word } \\
\text { utterance-morpho- } \\
\text { logically inappro- } \\
\text { priate } \\
\text { C) More than one-word } \\
\text { utterance-syntacti- } \\
\text { cally and grammati- } \\
\text { cally appropriate }\end{array}$ & $\begin{array}{l}\text { Primary communication } \\
\text { function } \\
\text { A) Verbal stimulation- } \\
\text { unrelated to the form } \\
\text { and content of the } \\
\text { child's utterance } \\
\text { 1) Behavior request } \\
\text { 2) Information re- } \\
\text { quest } \\
\text { 3) Give information } \\
\text { 4) Social speech } \\
\text { 5) Nonverbal commu- } \\
\text { nication } \\
\text { B) Response to the form } \\
\text { or content of child's } \\
\text { utterance }\end{array}$ & $\begin{array}{l}\text { Relationship of utterance } \\
\text { to communicative con- } \\
\text { text } \\
\text { A) Initiate new topic } \\
\text { B) Elaborate own topic } \\
\text { C) Respond to other's } \\
\text { topic } \\
\text { D) Exact repetition } \\
\text { E) Partial repetition } \\
\text { F) Semantic repetition } \\
\text { G) No apparent rela- } \\
\text { tionship to topic }\end{array}$ \\
\hline
\end{tabular}


according to whether utterances are a response to the child's utterances or provide verbal stimulation that is unrelated to the child's utterances. Verbal stimulation is further subdivided into the categories of behavior request, information request, give information, social speech, and nonverbal communication.

Topic is a discourse parameter that classifies each utterance according to its relationship to the topic of conversation. This includes initiating a new topic, elaborating one's own topic, responding to the other's topic, exact repetition, partial repetition, and semantic repetition. The categories syntactic integrity, functional content, and topic are different forms of self-imitation.

Neither of the two children produced verbal utterances during any of the six sessions. Each of their nonverbal vocalizations were coded according to the sequential relationship of the vocalization to the mother's vocalization and according to whether the child's vocalization was perceived as being meaningful or nonmeaningful.

\section{Results}

The following analysis is focused on the parameters of frequency of maternal and child utterances and the syntactic complexity, functional content, and topic of maternal utterances. In all instances the frequency with which each of these parameters were observed is described first, followed by the results of the statistical comparisons that were made to detect significant differences between subjects and across time. In the final part, a sequential analysis is reported which investigated whether the changes in the functional content of maternal utterances and in the frequency of child utterances that occurred during the course of the study could be explained in terms of a linear sequential model.

Unless otherwise indicated, a log linear procedure (Dixon \& Brown, 1977) was used to make statistical comparisons, because this is an effective statistical procedure for analyzing nominal data. Interpretations of simple effects were based on a simple comparison of mean scores.

\section{Frequency of utterances}

A total of 3,679 utterances were recorded for both dyads, of which $\mathbf{2 8 2}$ or $7.7 \%$ were not analyzable. The total number of analyzed utterances was 2,317 for Pair A and 1,082 for Pair B, which includes 1,415 utterances for Mother A, 902 utterances for Child A, 940 utterances for Mother $B$, and 142 utterances for Child B. The differences between the frequency of utterances produced by Mother $A$ and that of Mother B were highly significant $(p<.001)$. Although both mothers increased their frequency of utterances during the course of the year $(p<.001)$, the rate of increase was greater for Mother A than for Mother B.

There was a marked discrepancy between

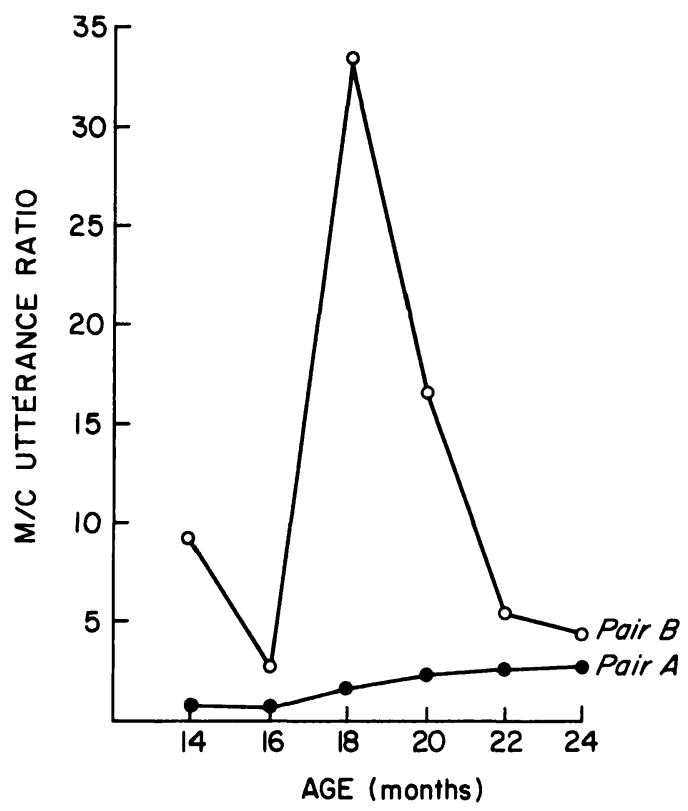

Figure 1. Ratio of maternal utterances to child utterances $(\mathrm{M} / \mathrm{C})$ at the six observational sessions. 
the two dyads in the ratio of maternal utterances to child utterances produced at each of the observations. As is indicated in Figure 1, over the entire six sessions Mother A produced an average of 1.7 utterances for each of her child's utterances, whereas Mother B produced six utterances for each of her child's utterances. These findings indicate that although both mothers produced more utterances than their children, Mother B dominated the communication exchange with her child during each of the observations far more than did Mother A. In part, this discrepancy is accounted for by the fact that Child B seldom vocalized during some of the sessions.

\section{Syntactic complexity}

An analysis of variance was used to make statistical comparisons of MLUs. The MLUs for the two mothers at each observation are depicted in Figure 2. The average MLU for the entire year was 3.29 (range 3.00-3.75) for Mother A and 2.65 (range 2.2-3.2) for Mother $B$. Although the MLU was consistently higher for Mother A than for Mother B at each observation $(p<.01)$, it increased significantly for both mothers over the course of the

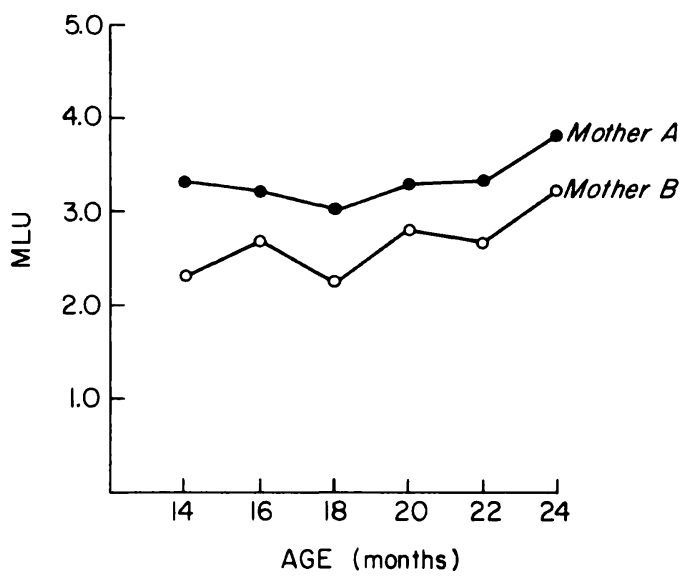

Figure 2. Mean length of utterance (MLU) in morphemes of maternal language at the six observational sessions.

year $(p<.01)$, and the rate of increase was greater for Mother B than for Mother A $(p<.01)$.

The syntactic integrity of each mother's utterances is depicted in Figure 3. There were no significant differences between the two mothers in the proportion of one-word utterances they produced for the entire year $(p>.05)$, and the rate of producing one-word utterances did not change over time $(p>.05)$.
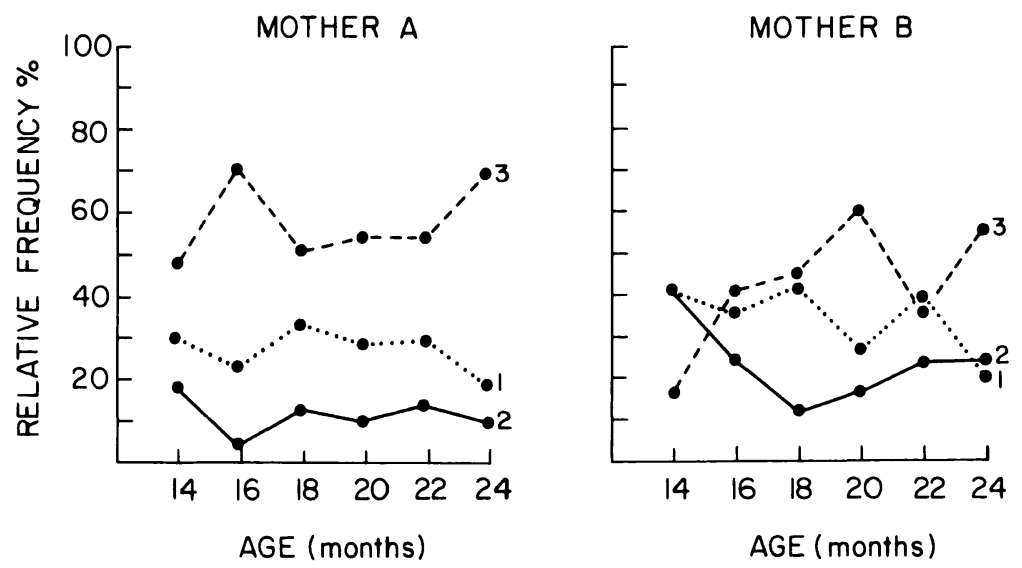

Figure 3. Relative frequency measures of syntactic integrity for maternal language at the six observational sessions. $1=$ One-word utterance; $2=$ More than one-word utterance, ungrammatical; $3=$ More than one-word utterance, grammatical. 
Both of the mothers in the study increased the complexity and syntactic integrity of their utterances over the course of the year.

Mother B produced relatively more ungrammatical utterances than Mother A did $(p<.01)$, although for both mothers the proportion of ungrammatical utterances decreased over time $(p<.05)$, and the rate of decrease was significantly greater for Mother B than for Mother A $(p<.05)$. Mother A produced significantly more grammatical utterances than Mother B $(p<.001)$, and both mothers increased their production of grammatical utterances over time $(p<.01)$. The rate of increase was greater for Mother $B$ than for Mother A $(p<.01)$.

In general, the analysis of the syntax of maternal utterances indicated the following:

- Mother A consistently produced more complex and better formed utterances than Mother B did.
- Both mothers increased the complexity and syntactic integrity of their utterances over the course of the year.

- The changes in syntax during the year were more pronounced for Mother B than for Mother A.

\section{Functional classification}

Table 2 depicts the relative frequency with which each functional category was produced at each observational session. For both mothers an average of $32 \%$ of their utterances were coded behavior requests; $23 \%$ were coded information requests; $22 \%$ were coded give information; $11 \%$ were coded social speech; $6 \%$ were coded nonverbal communication; and $6 \%$ were coded response to child's utterance. Thus very little of either mother's communication was directed at the form or content of the child's vocalizations, and the majority of their utterances provided the child with various forms of verbal stimulation.

There were no significant differences between Mother A and Mother B in the proportion of their utterances classified as behavior request $(p>.05)$. For both mothers the

Table 2. Relative frequency of maternal language functions

\begin{tabular}{|c|c|c|c|c|c|c|c|}
\hline \multirow{2}{*}{$\begin{array}{c}\text { Language } \\
\text { function }\end{array}$} & \multirow[b]{2}{*}{ Subject } & \multicolumn{6}{|c|}{ Time (in months) } \\
\hline & & 14 & 16 & 18 & 20 & 22 & 24 \\
\hline Behavior & $\mathbf{A}$ & 31.0 & 34.2 & 43.7 & 26.3 & 29.1 & 26.2 \\
\hline request & B & 18.5 & 33.3 & 32.0 & 48.7 & 29.2 & 34.2 \\
\hline Information & $\mathbf{A}$ & 18.7 & 27.8 & 19.2 & 22.3 & 23.6 & 28.2 \\
\hline request & B & 11.1 & 9.5 & 9.2 & 17.2 & 26.3 & 22.3 \\
\hline Give & A & 18.2 & 13.4 & 17.4 & 24.7 & 27.4 & 24.0 \\
\hline information & B & 15.7 & 17.5 & 32.1 & 18.1 & 22.6 & 26.4 \\
\hline \multirow[t]{2}{*}{ Social speech } & A & 9.4 & 5.9 & 9.0 & 14.0 & 9.5 & 7.9 \\
\hline & B & 33.3 & 25.4 & 11.5 & 12.9 & 13.1 & 5.9 \\
\hline Nonverbal & A & 6.1 & 7.0 & 1.8 & 4.4 & 2.4 & 4.5 \\
\hline communication & B & 13.9 & 12.7 & 14.5 & 3.0 & 5.8 & 9.7 \\
\hline Response to child's & $A$ & 16.6 & 11.8 & 9.0 & 8.2 & 8.1 & 9.0 \\
\hline communication & B & 7.4 & 1.6 & 0.7 & 0.0 & 2.9 & 1.5 \\
\hline
\end{tabular}


proportion of behavior requests increased during the first 6-8 months and then decreased during the remainder of the year $(p<.01)$. Mother A produced a greater proportion of information requests than did Mother B $(p<.01)$, and both mothers increased their rate of production of information requests throughout the course of the year $(p<.01)$.

The proportion of maternal utterances classified as give information did not differ significantly either between the two mothers $(p>.05)$ or across the six observational sessions $(p>.05)$. Mother B had a greater proportion of social speech $(p<.05)$ and nonverbal communication $(p<.001)$ than did Mother A, but the rate of production of both of these categories did not change over the course of the study. Mother A had significantly more utterances classified as response to the child's utterance than Mother B did $(p<.001)$, and the proportion of utterances classified in this category decreased significantly over time $(p<.01)$.

In summary, the analyses of the functional content of maternal speech indicated that there were consistent differences between the mothers in the relative rate with which they produced various categories of functional speech during the course of the study. A greater proportion of the utterances of Mother A were classified as information requests and response to the child's utterances, whereas a greater proportion of the utterances of Mother $B$ were classified as social speech and nonverbal communication. For both mothers there was a significant developmental increase in the proportion of information requests and significant decreases in behavior requests and responding to the child's utterances.

\section{Topic}

The relative frequency that maternal utterances were classified into each of the seven topic categories at each observation are reported in Table 3. For both mothers an average of $29 \%$ of all utterances were classified as initiate new topic; $30 \%$ as elaborate own topic; $7 \%$ as respond to other's topic; $18 \%$ as exact repetition; $9 \%$ as semantic repetition; $4 \%$ as partial repetition; and $2 \%$ as no apparent relationship to topic.

There were no significant differences between the two mothers in the proportion of utterances classified in four of the seven categories: initiate new topic, elaborate own topic, exact repetition, and partial repetition $(p>.05)$. However, a greater proportion of utterances of Mother A were classified as respond to other's topic and semantic repetition $(p<.01)$, whereas a greater proportion of the utterances of Mother B were classified as no apparent relationship to topic $(p<.01)$.

For both mothers there was a decrease in initiate new topic $(p<.01)$ and an increase in elaborate own topic $(p<.01)$ over the course of the six sessions. No significant developmental changes were found for any of the other topic categories $(p>.05)$.

In summary, the analyses of topic indicate that a greater proportion of the utterances of Mother A were classified as respond to other's topic and semantic repetition, whereas a greater proportion of the utterances of Mother B were classified as unrelated to the topic of conversation. For both mothers there were developmental increases in the frequency of sustained communication episodes with their children, as was indicated by the decreased proportion of utterances classified as initiate new topic and the increased proportion of utterances classified as elaborate own topic.

\section{Sequential analyses}

Linear sequential analyses were computed to examine whether the differences between the mothers and the developmental changes that occurred in the functional content of maternal speech might be explained partly by the fact that the children differed in the frequency of their vocalizations and also 
Table 3. Relative frequency of topic categories in maternal speech

\begin{tabular}{|c|c|c|c|c|c|c|c|}
\hline \multirow{2}{*}{$\begin{array}{c}\text { Topic } \\
\text { category }\end{array}$} & \multirow[b]{2}{*}{ Subject } & \multicolumn{6}{|c|}{ Time (in months) } \\
\hline & & 14 & 16 & 18 & 20 & 22 & 24 \\
\hline \multirow[t]{2}{*}{ Initiate new topic } & $\mathbf{A}$ & 27.1 & 23.8 & 39.2 & 41.5 & 39.2 & 10.6 \\
\hline & B & 42.0 & 61.9 & 14.3 & 18.1 & 49.6 & 17.8 \\
\hline Elaborate & A & 21.5 & 25.9 & 20.5 & 22.4 & 20.6 & 49.2 \\
\hline own topic & B & 9.2 & 17.5 & 44.4 & 41.4 & 20.4 & 41.9 \\
\hline \multirow{2}{*}{$\begin{array}{l}\text { Respond to } \\
\text { other's topic }\end{array}$} & $\mathbf{A}$ & 16.6 & 15.3 & 7.8 & 8.5 & 8.1 & 9.2 \\
\hline & B & 5.9 & 1.6 & 7.5 & 0 & 3.6 & 3.7 \\
\hline Exact & $\mathbf{A}$ & 14.4 & 14.2 & 16.3 & 14.3 & 14.5 & 16.8 \\
\hline repetition & B & 22.7 & 7.9 & 19.5 & 25.9 & 16.1 & 20.4 \\
\hline \multirow{2}{*}{$\begin{array}{l}\text { Semantic } \\
\text { repetition }\end{array}$} & $\mathbf{A}$ & 13.8 & 9.0 & 13.9 & 11.6 & 14.5 & 7.9 \\
\hline & B & 5.0 & 9.5 & 6.0 & 9.5 & 8.0 & 4.1 \\
\hline \multirow{2}{*}{$\begin{array}{l}\text { Partial } \\
\text { repetition }\end{array}$} & $\mathbf{A}$ & 6.6 & 6.3 & 2.4 & 1.4 & 3.0 & 4.1 \\
\hline & B & 5.9 & 1.6 & 3.8 & 2.6 & 2.2 & 6.3 \\
\hline \multirow{3}{*}{$\begin{array}{l}\text { No apparent } \\
\text { relationship } \\
\text { to topic }\end{array}$} & A & 0 & 5.3 & 0 & 0.0 & 0 & 2.4 \\
\hline & B & 9.2 & 0 & 4.5 & 2.6 & 0 & 5.9 \\
\hline & & & & & & & \\
\hline
\end{tabular}

increased their rates of vocalization during the course of the study. That is, might some of the observations regarding the functional content of maternal language, such as the increase in the variable request information, be explained by the fact that this characteristic of maternal speech is elicited by children's vocalizations?

The sequential analysis procedure, which was developed by Sackett (1977) and revised by Bakeman (1977), examines whether the conditional probability of a specific functional category of maternal speech occurring after each child vocalization is statistically greater than chance. The analysis also extends up to the fourth maternal utterance following each child vocalization and thus examines possible delayed maternal responses to child vocalizations.

Based on the analysis of all utterances for each of the dyads at 14 and 24 months, no significant conditional probabilities were observed between child vocalizations and spe- cific functional categories of maternal speech $(p>.05)$. It therefore appears that the way in which the mothers used language in speaking to their children could not be explained as a simple response to the child's vocalization. Rather, the differences between the mothers, and the developmental changes in the functional content of maternal language, seemed to be mediated by factors other than the expressive communication style of the infants.

\section{Discussion}

Homogeneity in the manner in which mothers speak to their children

The first question addressed in this study was whether the mothers of these children were similar in their styles of speaking to their children. The results of the data analyses indicated that although many of the language characteristics of the two mothers were similar, others varied considerably. Throughout the study Mother A spoke more frequently to 
her child, her utterances were more syntactically complex and better formed grammatically, she requested information from her child more frequently, and she was more responsive to her child's communication than Mother B. On the other hand, Mother B used more nonverbal communication, more social speech, and more speech that was unrelated to the topic of conversation than did Mother A.

The importance of the comparison of these two mothers is that their language was addressed to developmentally delayed children who were similar to each other in age, expressive language development, measured level of cognitive functioning, organic pathology, birth order, number of siblings, and social class. Thus, insofar as these children are representative of developmentally delayed children with similar characteristics, the assumption that mothers are homogeneous in the manner in which they speak to their developmentally delayed children is not supported by these data.

Since the study included only two subjects, there is insufficient data for identifying factors that may have contributed to the observed differences between these mothers. The findings of the study suggest that future research should assess multiple characteristics of mothers and their children that might contribute to differences in children's linguistic environment. Such research efforts could include assessing maternal variables, such as attitudes, psychological well-being, and acceptance of the child, as well as child variables, such as activity level, attention, responsivity, and temperament. The results clearly indicate, however, that Down's syndrome and developmental delay are not the sole factors that influence the maternal language environment. It is also apparent from the results of the sequential analysis that differences between mothers are not merely a response to differences in their children's vocalization patterns.

The critical question that cannot be
It is apparent from the results of the sequential analysis that differences between mothers are not merely a response to differences in their children's vocalization patterns.

answered directly from this study is whether the observed differences in maternal language can be expected to have either a positive or negative effect on the children's rate of language development.

There were several characteristics of the language of Mother A that could be expected to have a positive effect on her child's language development. Not only did Mother A provide more verbal stimulation to her child than Mother B, which, at least, Clarke-Stewart (1974) reported to be related to children's development, but also the content of Mother A's language was geared more toward objects or events in the immediate environment than was the content of the language of Mother B. In terms used by Nelson (1973) in describing maternal speech, the language of Mother A seemed to be more referential, whereas the language of Mother B seemed more expressive or focused on personal-social relationships. This observation is significant insofar as the data from Nelson's (1973) study suggest that during the second year, referential maternal speech may be more beneficial for promoting language development among normal children than is expressive maternal speech.

Other comparisons of the language of the two mothers suggested that Mother A had a more sensitive language orientation than Mother B. First, a larger proportion of the utterances of Mother A were well formed grammatically and thus provided her child with a larger percentage of grammatically appropriate models from which the rules of grammar could be induced. Well-formed, grammatical utterances have been repeatedly 
observed to be a major characteristic that differentiates mother-child speech from adult-adult speech (Broen, 1972; Snow, 1972).

Second, Mother A produced a greater proportion of semantic repetitions than Mother B did. Broen (1975) has proposed that this characteristic of maternal speech may be a way of demonstrating to a child how a familiar word might be substituted with a novel word and thus may be an effective strategy for teaching word meaning. In addition, semantic repetition may also be a means for demonstrating various grammatical devices to children.

Third, Mother A was more responsive to her child's nonverbal vocalizations than Mother B was. There are numerous potentially positive effects of this type of maternal responsiveness:

- It could lead to increases in children's rate of nonverbal vocalization.

- It could be an effective means for teaching the child some of the rudimentary laws of vocal communicative exchanges (Snow, 1977).

- It could provide a way of teaching a child that his or her vocalizations can be used to communicate his or her intention, particularly if the response of the mother begins to match the intention of the child (Bruner, 1974-75). Fourth, since compared with the utterances of Mother A, a greater proportion of the utterances of Mother B were classified as having no obvious relationship to the topic, Mother B's utterances had considerably less potential for communicating information to the child.

\section{Changes in the communication between mothers and their children over time}

The second question addressed in the study was whether there were changes in the quality of maternal speech which coincided with changes in the children's chronological age. Maternal language was analyzed at 2-month intervals from the time the children were 14 months until they were 24 months old. A from these different developmental points indicated that as the children grew older, several parameters of maternal speech increased, including frequency, syntactic complexity, grammatical completeness, the number of information requests, and the number of sustained episodes of communication. At the same time, there were decreases in the number of behavior requests as well as in the frequency with which the mothers responded to their children's vocalizations.

In general, these developmental findings are compatible with the maternal language data that have been reported in studies of mothers of normal children (Broen, 1972; Mahoney \& Seely, 1976; Newport, 1976; Phillips, 1973). It has been clearly documented that not only do mothers reduce their syntactic complexity while talking to young infants, but also as infants grow older and develop greater language competence, mothers increase the syntactic complexity of their language input to their child (Mahoney \& Seely, 1976).

Furthermore, the observed increase in information requests and decrease in behavior requests, as well as the increased number of sustained communication episodes, are phenomena that others have speculated to be related to increasing cognitive competence (Baldwin \& Baldwin, 1973; Mahoney \& Seely, 1976). Thus although the expressive language development of these children was extremely limited during the course of the study, the developmental changes in maternal language suggest that over the course of the year the mothers perceived their children to be more capable of responding to linguistic input and of processing information about the environment. These are the kinds of interactive changes that should occur if the mothers are sensitive and responsive to their children as young, developing human beings.

There was one change in maternal language 
that was inconsistent with the other findings in the study and that does not seem to be an adaptive response to language-learning children. Both mothers decreased their rate of responding to their children's nonverbal vocalizations from 14 to 24 months. This was indicated by both the analysis of the topic category as well as the analysis of functional content of maternal speech. It is possible that the unduly slow rate of language development of these children may have extinguished the tendency of their mothers to respond to the children's vocalizations during this period. If maternal responsiveness to children's language development is a critical parameter of maternal speech (Clarke-Stewart, 1974), then this is a potentially serious finding that merits followup investigation.

The developmental analyses of these two dyads is instructive not only in terms of identifying general trends, but also for looking at the individual differences between the two mothers. Even though the language stimulation provided by Mother B seemed to be less effective than that provided by Mother $A$, the changes in the language of the two mothers were in the same direction, and over the course of the year the rate of change for some variables was significantly greater for Mother B than for Mother A. An interpretation of this finding is that although the linguistic input that Mother B provided her child seemed to be somewhat deficient initially, she seemed to make marked improvements in her style of speaking to her child throughout the year. These findings suggest that for parents of handicapped children, maternal language style may not be a stable characteristic, but rather may be one that changes as parents continue to adjust to their child.

The results from this study may be summarized as follows:

- Mothers differ in the manner in which they speak to their Down's syndrome children.
- Their maternal language changes as their children grow older.

- Quality of maternal language is not necessarily a developmentally stable phenomenon.

These results indicate that the practice of analyzing the language of mothers of mentally retarded children as a group phenomenon ignores the potentially important individual differences that exist within this group. Even though many of these mothers may have difficulty interacting with their children, this is not a general characteristic of all mothers of mentally retarded children.

\section{THE TRANSACTIONAL MODEL OF DEVELOPMENT VERSUS THE MAIN EFFECTS MODEL}

The strategy of comparing groups of parents of mentally retarded children with groups of parents of nonretarded children is based partly on the main effects model of psychological research. This research strategy assumes that the behavior of a population (e.g., parents of Down's syndrome children) can be linked to one major variable (e.g., a Down's syndrome child) or that populations (e.g., parents) respond in a characteristic or homogeneous manner to major psychological or biological variables (e.g., Down's syndrome).

Sameroff and Chandler (1975) observed that the developmental outcome of high-risk infants cannot be explained adequately through this main effects model. Neither major care-giving variables, such as socioeconomic status, nor major neonatal disorders, such as prematurity or anoxia, are reliable predictors of children's outcomes in and of themselves. As Sameroff and Chandler proposed, the prediction of developmental outcome requires information about the nature of the child's transactions with his or her environment. 
Although conditions such as Down's syndrome inevitably seriously depress mental and language functioning, the transactional model of development may be as valid for children with this disorder as it is for other children. There is considerable variability in the rate in which Down's syndrome children develop, and it is likely that this variability is related to the ability of these children to engage in meaningful social interaction as well as the sensitivity and skill of their parents to respond to them and provide them with appropriate stimulation.
As researchers begin to apply the transac-

\section{REFERENCES}

Bakeman, R. Untangling streams of behavior: Sequential analyses of observational data. In G.P. Sackett (Ed.), Observing behavior (Vol. 2). Data collection and analysis methods. Baltimore: University Park Press, 1977.

Baldwin, C.P., \& Baldwin, A.L. Cognitive content of mother-child interaction. Unpublished manuscript, Cornell University, 1973.

Broen, P.A. The verbal environment of the languagelearning child. American Speech and Hearing Association Monographs, 1972 (Whole No. 17).

Broen, P.A. What children hear: A description of the speech addressed to children. Paper presented at the annual meeting of the American Association of Mental Deficiency, Portland, Ore., May 1975.

Brown, R. A first language: The early stages. Cambridge, Mass.: Harvard University Press, 1973.

Bruner, J.S. From communication to language-a psychological perspective. Cognition, 1974-75, 3, 255-287.

Buckhalt, J.A., Rutherford, R.B., \& Goldberg, K.E. Verbal and non-verbal interaction of mothers with their Down's syndrome and non-retarded infants. American Journal of Mental Deficiency, 1978; 82, 337-343.

Buium, N., Rynders, J., \& Turnure, J. Early maternal linguistic environment of normal and Down's syndrome language learning children. American Journal of Mental Deficiency, 1975, 79, 52-58.

Clarke-Stewart, K.A. Interactions between mothers and their young children: Characteristics and consequences. Monographs of the Society for Research in Child Development, 1974, 38 (6,7, Serial No. 153).

Cross, T.G. Mothers' speech adjustments: The contribution of selected child listener variables. In C.E. Snow \& C.A. Ferguson (Eds.), Talking to children. Cambridge, Mass.: Cambridge University Press, 1977.

Cross, T.G. Mothers' speech and its association with rate of tional model of development toward understanding mental retardation and delayed language development, they must shift their focus from determining whether these phenomena are similar to or different from normal development to determining the nature of factors that create mother-child transactions that optimize the rate and quality of development of seriously impaired children. The investigation of individual differences in parent-child interaction, as exemplified in this study, is a first step toward this goal. linguistic development in young children. In $\mathbf{N}$. Waterson \& C. Snow (Eds.), The development of communication. New York: John Wiley \& Sons, 1978.

Dixon, W.J., \& Brown, M.B. (Eds.). BMD Biomedical Computer Programs: P-Series. Los Angeles: University of California Press, 1977.

Furrow, D., Nelson, K., \& Benedict, H. Mothers speech to children and syntactic development: Some simple relationships. Journal of Child Language, 1979, 6, 423442.

Mahoney, G.J. Ethological approach to delayed language acquisition. American Journal of Mental Deficiency, $1975,80,139-148$.

Mahoney, G.J., \& Petersen, G. The Maternal Language Classification Scale. New York: Ford Foundation, 1980 (ERIC Document Reproduction Service No. ED 184 718).

Mahoney, G.J., \& Seely, P.B. The role of the social agent in language acquisition: Implications for language intervention. In N.R. Ellis (Ed.), International review of research in mental retardation (Vol. 8). New York: Academic Press, 1976.

Moerk, E. Processes of language teaching and training in the interactions of mother-child dyads. Child Development, 1976, 47, 1064-1078.

Nelson, K. Structure and strategy in learning to talk. Monographs of the Society for Research in Child Development, 1973, 38 (1-2, Whole No. 149).

Newport, E.L. Motherese: The speech of mothers to young children. In N. Costello, D. Pisoni, \& G. Polts (Eds.), Cognitive theory (Vol. 2). Hillsdale, N.J.: Erlbaum, 1976.

Petersen, G., \& Sherrod, K. Relationship of maternal language to language development and language delay 
TOPICS IN EARLY CHILDHOOD SPECIAL EDUCATION / APRIL 1983

of children. American Journal of Mental Deficiency, 1982, 96, 391-398.

Phillips, J.R. Formal characteristics of speech which mothers address to their children. Child Development, 1973, 44, 182-185.

Rondal, J.A. Maternal speech to normal and Down's syndrome children matched for mean length of utterance. In C.E. Meyers (Ed.), Quality of life in severely and profoundly mentally retarded people: Research foundations for improvement. Washington, D.C.: American Association on Mental Deficiency, 1978.

Sackett, G.P. Measurement in observational research. In
G.P. Sackett (Ed.), Observing behavior (Vol. 2) Data collection and analysis methods. Baltimore: University Park Press, 1977.

Sameroff, A.J., \& Chandler, M.J. Reproductive risk and the continuum of caretaker casualty. In F.D. Herowitz (Ed.), Review of child development research (Vol. 4). Chicago: University of Chicago Press, 1975.

Snow, C.E. Mother's speech to children learning language. Child Development, 1972, 43, 549-565.

Snow, C. The development of conversation between mothers and babies. Journal of Child Language, 1977. 4, 1-22. 